\title{
Study on 'Value Grade' Rating System for Evaluating the Value of Technological Property Right in China
}

\author{
Yan Liu* \\ School of Economic\& Management, South China Normal \\ University, Guangzhou, 510006, China \\ Email:marsriver@126.com, \\ *Corresponding author: Yan LIU
}

\author{
Qi-Hui Su \\ School of Economic\& Management, South China \\ Normal University, Guangzhou, 510006, China \\ Email: 1595009982@qq.com
}

\begin{abstract}
The paper proposed a concept of value grade to assess value of technological property right from four aspects: law value, economic value, technologcal value and market value. Firstly, the paper analyzes the influencing factors for the value of technological property right and formed a indexes system to analyze the value of technological perperty right. Some methods of calculating the value of indexes had been proposed ; Secondly, using Analytic Hierarchy Process method, the paper estalished an model to rate value grade of technological property right. The paper finally examined the rating system by calculating value grade of two technological property rights from two LED lighting manufactories in Guangdong province in China, and the method has been proven to be a feasible and practical way to evaluate the value of technological property right.
\end{abstract}

Keywords-Technological Property Right, Index System, Value Grade.

\section{INTRODUCTION}

Technological property right includes a series of technological assets such as patent, nonpatented technology and industrial copyright, etc.. Because index system that evaluating the value of technological property right influences the accuracy of evaluation, the paper researches the indexes that influencing the value of technological property right firstly, and then proposes some methods to calculate the value of those indexes. Finally, using AHP method, the paper formed a model to calculate value grade of technological property right.

The first achievement in indexes designing for evaluating technological property right is Patent Scoring Method, which was proposed by CHI research company in America.CHI method designed indexes from five aspects: current impact index(CII) , patent citation, technology strength, technology life cycle and science linkage[1]. M.Reitzig (2004)choiced thirteen indexes such as patent life, company's market value, size of patent family and technical coverage,etc. from empirical study on value of 23 technological property rights[2]. J. O. Lanjouw\&M. Schankerman (2004) found that adopting composite indexes can decrease deviation in evaluating the value of technological property right [3]. Xiao-Li WAN \& Xue-Zhong ZHU (2008) formed a seventeen indexes system from three aspects :technology value, market value and right value, and adopted fuzzy comprehensive evaluation method to rate the value of patents[4]. Ming WEN,He SHUN\&Hong-Yi TU ( 2012 ) formed value evaluating system from five aspects: leading degree of patent technology, industrialization of patent technology, sufficiency of patent protection, defense of patent right and stability of patent[5].In 2012, Patent Value Degree (PVD)[6] was published in China, and it's a result of cooperation by State Intellectual Property Office and China Technology Exchange, and it evaluates the value of patent from law, technology and economic aspects which including eighteen second lever indexes. Aboving researches contribute a lots to evaluate the value of technological property right, but there exist four kinds of problems in setting rating indexes for China. The first is that some indexes setting by foreign researchers is not suitable in China, such as index of current impact index (CII) and size of patent family index; The second is that some of indexes are difficult to quantifed in evaluation, such as patent strategy index and sufficiency of patent protection index; The third is that in China, technological property rights are diveded into three types when they are authorized: invention type, new utility type and appearance design type, and each type reflects different lever of value for technological property rights, and the existing researches had not considing the characteristic in China; The fourth is that the range of technological property right is larger than that of patent, and the existing researches almost pain more attention on evaluating value of patent. So, the paper aims to establish a rating system which is feasible and practical to evaluate the value of technological property right in China.

\section{FORMING INDEX SYSTEM EVALUATING THE VALUE OF TECHNOLOGICAL PROPERTY RIGHT \\ In our paper, the index system evaluating the value of technolotical property right is formed from four aspects in first lever: law value, economic value, technologcal value and market value, and there are eighteen indexes in secend lever. Some methods calculating the value of each second lever indexes have been proposed. And we have some new ideas in setting and measuring some indexes, such as methods to calculate indexes in economic value lever, and that of patent class index measurement which belongs to technological value, and measurement of industry developing prospects index in market value lever. All of them are shown in table 1 as follows.}




\section{A MODEL TO ASSESS THE VALUE OF A TECHNOLOGICAL PROPERTY RIGHT}

Structuring the Decisional Problem into a Hierarchical Model and Making Pair-Wise Comparisons and Obtaining the Judgmental Matrix.

In this part, the paper proposed a concept of value grade to evaluate the value of a technological property right. We use Analytic Hierarchy Process as a means to assign weights to each criteria and sub-criteria. Designing the hierarchical structure of the decisional problem, it is structured as in figure 1 .

The paper divided the decisional problem into three levels: First is the all objective related to the assessing of the value of a technological property right(lever V); Second is the primary criteria for assessing the value of a technological property right (lever $\mathrm{Ci}, \mathrm{i}=1--4)$; Third is the sub-criteria that operationalize the primary criteria(lever $B_{k}$, $\mathrm{k}=1--18$ ).

And then we introduce pairwise comparisons aimed at determining the relative importance of the criteria and sub-criteria. In this paper, managerial judgments are expressed on an integer scale ranging from 1 to 9 , in order to avoid violation of the critical principle of proportionality. The semantic scale used in AHP is shown in table 2 as follows.

\section{A. Testing Consistency of Comparisons}

Once the judgemental matrix(matrix A) of comparisons of criteria with respect to the goal is available, it has been generally agreed(Saaty,1980) ${ }^{[7]}$ that priorities of criteria can be estimated with Eq.1 by finding the principal eigenvector $\omega$ of the matrix A as follow:

$$
\mathrm{Aw}=\lambda_{\max } \omega
$$

When the vector $\omega$ is normalized, it becomes the vector of priorities of the criteria with respect to the goal. $\lambda_{\max }$ is the largest eigenvalue of the matrix $\mathrm{A}$ and the corresponding eigenvector $\omega$ contains only positive entries.

The consistency of the judgmental matrix can be determined by a measure called the consistency ratio(CR), defined as Eq. 2 as follow:

$$
C R=\frac{C I}{R I}
$$

Where CI is called the consistency index and RI, the Random Index.CI is defined as Eq. 3:

$$
C I=\frac{\left(\lambda_{\max }-n\right)}{(n-1)}
$$

RI is the consistency index of a randomly generated reciprocal matrix from the 9-point scale, wity reciprocals forced. Saaty ( 1980)[7] has provided average consistencies (RI value)of randomly generated matrices(up to size $11 \times 11$ )for a sample size of 500.The RI values for matrices of different sizes are shown in table 3 .

If $\mathrm{CR}$ of the matrix is higher, it means that the input judgements are not consistent, and are not reliable. In general, a consistency ratio of 0.10 or less is considered acceptable.

From information in figure 1 and table 1 , we can calculate the priorities of assessed technological property right with respect to each criteria and sub-criteria by solving matrix equations that translates the pairwise comparison into weights.

\section{B. Calculating Sub-Value of Lever C and Total Value Grade of Lever $V$}

The paper calculates the overall value grade of a technological property right by substituting each weights into corresponding indexes.

Concerning value grade of lever $\mathrm{C}$, for example, the value grade of lever $\mathrm{C}_{1}\left(\mathrm{~V}_{\mathrm{C} 1}\right)$ can be calculated with Eq. 4 as follow:

$\mathrm{V}_{\mathrm{C} 1}=\sum_{\mathrm{K}=1}^{4}\left(\mathrm{~B}_{\mathrm{k}} \times\right.$ local priority of lever $\mathrm{B}_{\mathrm{k}}$ with respect to lever $\left.\mathrm{C}_{1}\right)$.

So, for lever $C_{i}$, the value grade of lever $C_{i}\left(V_{C i}\right)$ can be calculated with Eq. 5 as follow:

$\mathrm{V}_{\mathrm{Ci}}=\sum_{\mathrm{K}=\mathrm{m}}^{\mathrm{n}}\left(\mathrm{B}_{\mathrm{k}} \times\right.$ local priority of lever $\mathrm{B}_{\mathrm{k}}$ with respect to lever $\left.\mathrm{Ci}\right)$.

Where $m$ is the beginning number of $k$ in $B_{k}$, and $n$ is the endding number of $\mathrm{k}$ in $\mathrm{B}_{\mathrm{k}}$.

Therefore, value grade of lever $\mathrm{V}\left(\mathrm{V}_{\mathrm{V}}\right)$ can be calculated with Eq. 6 as follow:

$\mathrm{V}_{\mathrm{V}}=\sum_{\mathrm{i}=1}^{4}\left(\mathrm{~V}_{\mathrm{ci}} \times\right.$ local priority of lever $\mathrm{C}_{\mathrm{i}}$ with respect to lever $\left.\mathrm{V}\right)$.

\section{Assigning Weights to Each Criteria and Sub-Criteria}

Using expert-consulting method, we formed judgement matrix to assign weights to criterion level in table 4 as follows. And the results of pairwise comparisons in table 4 is from consulting to researchers who are professornal in study of technological property right.

Because $\mathrm{CR}<0.1$, we can conclude that the input judgements are consistent and reliable, thus we get the weights and orders of $\mathrm{C}$ factors $(\mathrm{C} 1, \mathrm{C} 2, \mathrm{C} 3, \mathrm{C} 4)$ of criterion level from table 4,that is : $\mathrm{V}=(\mathrm{C} 1, \mathrm{C} 2, \mathrm{C} 3$, C4 $)=(0.1192,0.2517,0.4720,0.1571)$.

Using the same method, we get each factors's weight in each sub-criteria levers as follows:

$$
\begin{aligned}
\mathrm{C}_{1} & =\left(\mathrm{B}_{1}, \mathrm{~B}_{2}, \mathrm{~B}_{3}, \mathrm{~B}_{4}\right)=(0.1386,0.2832,0.0782,0.5000) ; \\
\mathrm{C}_{2} & =\left(\mathrm{B}_{5}, \mathrm{~B}_{6}, \mathrm{~B}_{7}\right)=(0.5922,0.1707,0.2371) ; \\
\mathrm{C}_{3} & =\left(\mathrm{B}_{8}, \mathrm{~B}_{9}, \mathrm{~B}_{10}, \mathrm{~B}_{11}, \mathrm{~B}_{12}, \mathrm{~B}_{13}, \mathrm{~B}_{14}\right) ; \\
& =(0.1056,0.1983,0.2212,0.0641,0.2049,0.0203,
\end{aligned}
$$


$0.1856)$;

$\mathrm{C}_{4}=\left(\mathrm{B}_{15}, \mathrm{~B}_{16}, \mathrm{~B}_{17}, \mathrm{~B}_{18}\right)=(0.3112,0.1894,0.2703,0.2291)$.

Each of $\mathrm{CR}$ value of aboving judgement matrixs is smaller than 0.1 , so the orders of each uni-lever have satisfactory consistency also.

\section{APPLICATION OF THE MODEL}

With the proposed method, we calculate the value grade of two kinds of technological property right. One of which is A kind of LED circle light source, which belongs to practical and new type technological property right, and was invented by CY company, a LED lighting manufactury in Guangzhou. The other is A kind of highly colored lighting diode and its manufactory method, which belongs to invention type technological property right, and was invented by MLS company, a LED lighting manufactury located in Zhongshan. Using above evaluating model, we've calculated their value grade. The valeu grade of the first technological property right is 4.2361 and the other is 6.6157 , which is much higher than the first owing to that it has been authorized and it belongs to a higher degree of technological property right, and MLS company had invested more cost to invent it than that of CYcompany.

\section{v. CONCLUSION}

The paper designed value grade rating system to evaluate internal value of technological property right from four aspects: law value, economic value, technological value and market value, and had set a series of sub-indexes under the four indexes. Using AHP method, the paper assigned weights to each criteria and sub-criteria, and finally founded a practical evaluation model. The method has been proven to be a feasible and practical way to evaluate the value of a technological property right through application.

\section{ACKNOWLEDGEMENT}

This research was financially supported by the Science and Technology Planning Project Foundation of Science and Technology Agency of Guangdong Province, China under Grant 2015A030401085. And it's also supported by the Accounting Research Project of Finance Department of Guangdong Provance, China under Grant 2015A59.

\section{REFERENCES}

[1]Narin F. Patent bibliometrics.Scientometrics, 1994,vol.30(1):pp147-155.

[2]Markus Reitzig. Improving patent valuations for management purposes-validating new indicators by analyzing application rationales. Research Policy ,2004,vol.33:pp935-957.

[3]Jean O. Lanjouw \& Mark Schankerman. Protecting intellectual property rights: are small firms handicapped?.The Journal of Law \& Economics,2004,vol.47,pp45-74.

[4] Xiao-Lii WAN, Xue-Zhong ZHU. The index system and fuzzy comprehensive evaluation of patent value. Science Research Managment,2008(2):pp185-191.

[5]Ming WEN, He SUN, Hong-Yi TU. Fuzzy synthetic evaluation model. Statistics and Decision,2012(17) :pp77-80.

[6]STATE INTELLUECUAL PROPERTY OFFICE OF THE P.RC,CHINA TECHNOLOGY EXCHANGE.Patent Value Degree,PVD. Intellectual Property Publishing Housing, 2012.

[7]Satty,T.L.The analytic hierarchy process.McGraw-Hill,New York.1980. 
TABLE I. INDEX SYSTEM FOR EVALUATING VALUE OF TECHNOLOGICAL PROPERTY RIGHT AND THEIR MEASUREMENT METHODS

\begin{tabular}{|c|c|c|}
\hline First order indexes & Secend order indexes & Measuring methods of the indexes \\
\hline \multirow{4}{*}{ Law value } & $\begin{array}{l}\text { warranted assertibility of technolotical } \\
\text { property right infringement }\end{array}$ & Is 1 , No. 0 \\
\hline & Period of validity & number of years \\
\hline & Multi Country application & Is 1 , No. 0 \\
\hline & $\begin{array}{l}\text { Status of technological property right } \\
\text { licensing }\end{array}$ & Is 1 , No. 0 \\
\hline \multirow{3}{*}{ Economic value } & Cost of investing & $\begin{array}{l}\text { Natural logarithm of the amount of book } \\
\text { value for the technological property right. }\end{array}$ \\
\hline & Cost of application & $\begin{array}{l}\text { Natural logarithm of the amount of } \\
\text { applicating fee. }\end{array}$ \\
\hline & Cost of transaction & $\begin{array}{l}\text { Natural logarithm of the amount of transaction } \\
\text { fee. }\end{array}$ \\
\hline \multirow{7}{*}{$\begin{array}{l}\text { Technological } \\
\text { value }\end{array}$} & science linkage & $\begin{array}{l}\text { Natural logarithm of the amount of } \\
\text { technolotical property right citations }\end{array}$ \\
\hline & Technology life cycle & $\begin{array}{l}\text { The median age of all cited technolotical } \\
\text { property right / The sum of the age of the } \\
\text { cited technological property right. }\end{array}$ \\
\hline & technology maturity & Whether industrialization, Is 1, No. 0 \\
\hline & Patent class & $\begin{array}{l}\text { Innovation type give } 3 \text { score, new utility type } \\
\text { give } 2 \text { score and appearance design type give } \\
1 \text { score. }\end{array}$ \\
\hline & Substitutability & $\begin{array}{l}\text { Whether there exists alternative technologies, } \\
\text { Is } 1 \text {, No. } 0 .\end{array}$ \\
\hline & Transfer times & Actual transfer times. \\
\hline & Supporting technology dependence & Is 1, No. 0 \\
\hline \multirow{4}{*}{ Market value } & Industry developing prospects & $\begin{array}{l}\text { Measuring industry life cycle of the firm who } \\
\text { owned the technological property right , and } \\
\text { industry life cycle can be divided into three } \\
\text { stages: developing life stage(give } 2 \text { score), } \\
\text { maturity life stage (give } 1 \text { score), declining life } \\
\text { stage (give } 0 \text { score) using Industry sification } \\
\text { Method. }\end{array}$ \\
\hline & market share & $\begin{array}{l}\text { Amount of market share of the firm who } \\
\text { owned the technological property right }\end{array}$ \\
\hline & $\begin{array}{l}\text { Competitors have the same kind of } \\
\text { technonogical property right }\end{array}$ & Is 1, No. 0 \\
\hline & $\begin{array}{l}\text { Policy adaptability of the technological } \\
\text { property right }\end{array}$ & Is 1, No. 0 \\
\hline
\end{tabular}




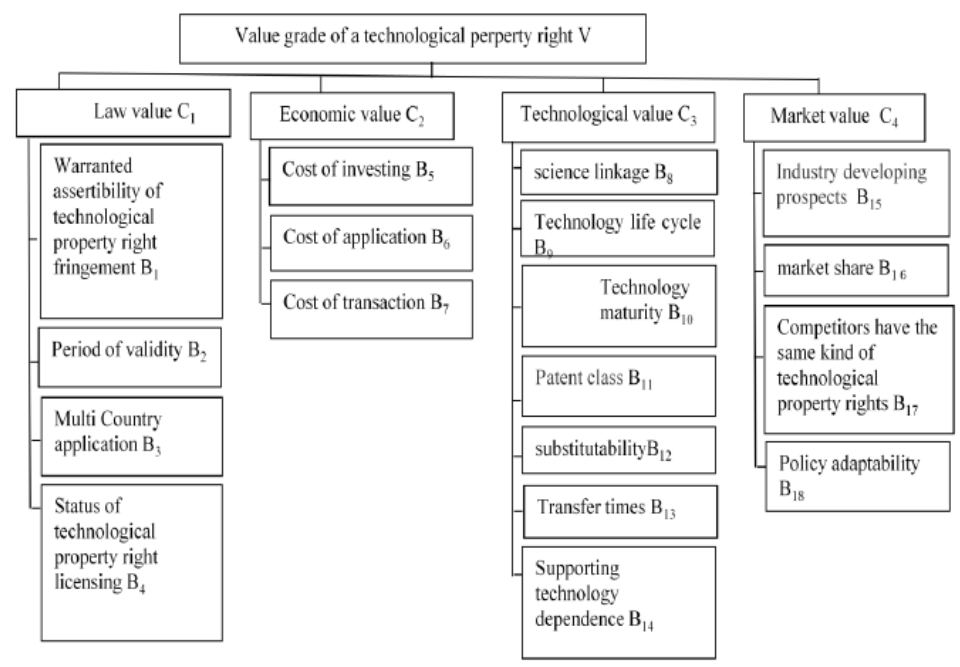

Fig. 1 The hierarchical structure of the decisional problem

TABLE II. THE SEMANTIC SCALE USED IN AHP

\begin{tabular}{|c|c|c|}
\hline Intensity of importance & Definition & Description \\
\hline 1 & Equal importance & Elements $\mathrm{Ai}$ and $\mathrm{Aj}$ are equally important \\
\hline 3 & Weak importance of Ai over $\mathrm{Aj}$ & Experience and judgement slightly favour $\mathrm{Ai}$ over $\mathrm{Aj}$ \\
\hline 5 & Strong important & Experience and judgement strongly favour $\mathrm{Ai}$ over $\mathrm{Aj}$ \\
\hline 7 & Demonstrated improtance & $\mathrm{Ai}$ is very strongly favoured over $\mathrm{Aj}$ \\
\hline 9 & Absolute importance & $\begin{array}{c}\text { The evidence favouring } \mathrm{Ai} \text { over } \mathrm{Aj} \text { is of the highest possible } \\
\text { order of affirmation }\end{array}$ \\
\hline $2,4,6,8$ & intermediate & $\begin{array}{l}\text { When compromise is meeded, values between two adjacent } \\
\text { judgements are used }\end{array}$ \\
\hline $\begin{array}{l}\text { Reciprocals of the above } \\
\text { judgements }\end{array}$ & $\begin{array}{l}\text { If Ai has one of the above judgements assigned } \\
\text { to it when compared wity } \mathrm{Aj} \text {, then } \mathrm{Aj} \text { has the } \\
\text { reciprocal value when compared with Ai. }\end{array}$ & A reasonable assumption \\
\hline
\end{tabular}

TABLE III. THE AVERAGE CONSISTENCIES OF RANDOM MATRICES(THE RANDOM INDES-RI-VALUES)

\begin{tabular}{|l|l|l|l|l|l|l|l|l|l|l|}
\hline Size & 1 & 2 & 3 & 4 & 5 & 6 & 7 & 8 & 9 & 10 \\
\hline RI & 0.00 & 0.00 & 0.58 & 0.90 & 1.12 & 1.24 & 1.32 & 1.41 & 1.45 & 1.49 \\
\hline
\end{tabular}


TABLE IV. JUDGEMENT MATRIX OF CRITERION LEVEL: VCI

\begin{tabular}{|l|l|l|l|l|l|l|}
\hline $\mathrm{V}$ & $\mathrm{C}_{1}$ & $\mathrm{C}_{2}$ & $\mathrm{C}_{3}$ & $\mathrm{C}_{4}$ & weight & order \\
\hline $\mathrm{C}_{1}$ & 1 & $1 / 2$ & $1 / 3$ & $1 / 2$ & 0.1192 & 4 \\
\hline $\mathrm{C}_{2}$ & 2 & 1 & $1 / 2$ & 2 & 0.2517 & 2 \\
\hline $\mathrm{C}_{3}$ & 3 & 2 & 1 & 4 & 0.4720 & 1 \\
\hline $\mathrm{C}_{4}$ & 2 & $1 / 2$ & $1 / 4$ & 1 & 0.1571 & 3 \\
\hline$\lambda_{\max }=4.2088 ; \quad \mathrm{CI}=0.0696 ; \quad \mathrm{RI}=0.90 ; \quad \mathrm{CR}=0.0773$ & & & \\
\hline
\end{tabular}

